\title{
Canto Coral - espaço de aprendizagem e desenvolvimento musical
}

\section{Choral singing- space for learning and musical development}

DOI: $10.46814 /$ lajdv2n5-011

Recebimento dos originais: 10/07/2020

Aceitação para publicação: 30/08/2020

Ana Claudia Reis

Doutora em Música (Processos Criativos) pela Universidade Federal do Rio de Janeiro -UFRJ/Escola de Música

Instituição: Secretaria Municipal de Educação- Prefeitura Municipal de Duque de Caxias- RJ

Endereço: R. Pref. José Carlos Lacerda, 1424 - Jardim Vinte e Cinco de Agosto, Duque de Caxias RJ- Brasil

E-mail: claussreis@gmail.com

\section{Maria José Chevitarese}

Doutora em Psicossociologia de Comunidade e Ecologia Social pela Universidade Federal do Rio de Janeiro -UFRJ/ Instituto de Psicologia

Instituição: Escola de Música da Universidade Federal do Rio de Janeiro -UFRJ/ Escola de Música Endereço: Rua do Passeio, 98 - Centro, Rio de Janeiro - RJ, Brasil

E-mail: zezechevitarese@gmail.com

\section{RESUMO}

Este artigo descreve parte dos resultados de pesquisa realizada com coralistas do Coral Infantil da UFRJ. A pesquisa se propõe a fazer uma investigação a respeito da utilização do canto coral como ferramenta de aprendizagem e desenvolvimento musical infanto-juvenil. Tomou-se como referencial, textos de John A. Sloboda e Leda Osório Mársico. Foram realizadas entrevistas com 15 crianças e adolescentes do Coral Infantil não estudantes de música para averiguar os conteúdos musicais absorvidos através do trabalho coral desenvolvido. Os resultados demonstraram que a atividade coral efetivamente contribuiu para o aprendizado e desenvolvimento musical do grupo de crianças e adolescentes analisados.

Palavras-chave: Aprendizagem, Desenvolvimento musical, Coro Infantil.

\begin{abstract}
This article describes part of the results of research carried out with choristers of the Children's Choir at UFRJ. The research proposes to carry out an investigation regarding the use of choral singing as a learning and musical development tool for children and adolescents. It was taken as a reference, texts by John A. Sloboda and Leda Osório Mársico. Interviews were carried out with 15 children and adolescents of the Children's Choir who were not music students to ascertain the musical contents absorbed through the choral work developed. The results showed that the choral activity effectively contributed to the learning and musical development of the group of children and adolescents analyzed.
\end{abstract}

Keywords: Learning, Musical development, Children's Choir. 


\section{INTRODUÇÃO}

O canto coral pode ser entendido como um espaço de aprendizagem e desenvolvimento do indivíduo em um contexto grupal, interacional, no qual o desenvolvimento da afetividade, da sociabilidade, da consciência e do pensamento crítico se dá associado ao desenvolvimento cognitivo da aprendizagem musical.

Nesse espaço crianças e adolescentes experimentam novas possibilidades e oportunidades de prática musical e, a partir deste fazer, poderão adquirir a consciência de que são mais capazes do que se imaginavam, entusiasmando-se com a perspectiva da possibilidade de novas conquistas e de seu desenvolvimento musical.

Crianças e adolescentes que procuram um coral geralmente o fazem por gostar de cantar e desejar buscar oportunidades de convívio social, num ambiente acolhedor, com trocas afetivas positivas, que proporcione contato com novos ambientes e novas aprendizagens.

Estes grupos normalmente não são homogêneos. A própria faixa etária já traz em si uma ampla heterogeneidade em termos de amadurecimento emocional, capacidade de concentração e de abstração, desenvolvimento intelectual, entre outros.

O canto coral tem sido considerado como atividade básica na educação musical por muitos educadores, entre eles, Amato (2010), Mathias (1986) e Fonterrada (2008). O canto coletivo, além de ser um meio acessível à educação musical por utilizar a voz humana como instrumento, possui elementos essenciais à formação musical como, por exemplo, o desenvolvimento da educação auditiva e respiratória, percepção rítmica, aquisição da leitura musical, compreensão fraseológica e melhoria da emissão vocal com qualidade de afinação. Proporciona ao coralista uma melhor compreensão musical e prazer baseado em apreciação e execução.

\section{REFERENCIAL PARA A PESQUISA}

A performance é um dos objetivos e a culminância do trabalho desenvolvido no canto coral. Ela revela o nível de aprendizagem e desenvolvimento musical do grupo.

Segundo Sloboda, a performance, ou execução musical num sentido mais amplo, abrange todos os tipos de comportamentos musicais manifestos. Num sentido mais restrito, é aquela na qual um executante ou grupo de executantes, interpreta música conscientemente para um público. O autor expõe três estágios de envolvimento com a partitura que permite o estudo da performance. (SLOBODA, 2008, p.87)

- Primeira leitura da partitura;

- Exposição continuada à partitura para aprimorar a execução; 
- Ensaio ou prática para aperfeiçoar e memorizar a partitura.

Considerando o processo de aprendizagem musical no coro, os três estágios expostos por Sloboda podem ser comparados com as fases descritas por Mársico (1979).

Segundo a autora, o processo de aprendizagem de uma obra vocal passa por três fases: recepção, assimilação e interpretação.

$\mathrm{Na}$ fase da recepção a música é apresentada pelo regente aos coralistas e trabalhada nos mínimos detalhes, observando questões importantes como respiração, articulação e emissão vocal.

$\mathrm{Na}$ fase da assimilação a obra musical em estudo é repetida várias vezes para aperfeiçoamento de detalhes técnicos. Pode-se repetir a música em diversos andamentos para verificar questões de afinação e segurança na execução.

A fase da interpretação é finalmente a fase de recriação da obra musical estudada. (MÁRSICO, 1979, p.54,55).

A primeira leitura da partitura corresponde a fase da recepção e ocorre no coro independente da aquisição de habilidades de leitura musical. Para um coralista não estudante de música, esta fase ocorre através de orientação e mediação do regente ou de outros coralistas que já possuem habilidade de leitura musical. O regente e os coralistas mais experientes passam a ser, num primeiro momento os olhos dos coralistas não estudantes de música.

O estágio de exposição continuada à partitura corresponde a fase da assimilação da obra musical e também é mediada pelo regente do grupo e coralistas mais experientes.

O estágio do ensaio ou prática corresponde a fase da interpretação e é um momento onde o coralista não estudante de música já possui autonomia para recriar a obra musical junto aos demais coralistas.

Para a pesquisa a respeito da aprendizagem e desenvolvimento musical dos coralistas não estudantes de música do Coral Infantil da UFRJ estudados, consideramos os três estágios descritos por Sloboda (2008) ou fases descritas por Mársico (1979).

\section{O CAMPO DE PESQUISA}

Para a realização desta pesquisa definiu-se como campo o Coral Infantil da Universidade Federal do Rio de Janeiro, onde foram realizadas observações dos ensaios, das apresentações e aplicação de questionário e entrevistas.

O Coral Infantil é um projeto de extensão universitária, idealizado pela professora Maria José Chevitarese e iniciado em março de 1989. Com 26 anos de atuação, o coral infantil já atendeu cerca 
de 1000 crianças e adolescentes com faixa etária entre 7 e 16 anos tendo realizado mais de 700 apresentações em variados espaços culturais como salas de concerto, teatros, museus, igrejas, escolas de música e programas de TV do Rio de Janeiro, de outros municípios e estados, além de apresentações internacionais.

O Coral Infantil foi criado inicialmente com o objetivo de dar apoio aos cursos de extensão universitária oferecidos pela Escola de Música da UFRJ. São eles: Musicalização Infantil, que atende crianças entre 7 e 8 anos, o curso Básico, que atende crianças e adolescentes com idades entre 9 e 14 anos e o curso Intermediário, que atende jovens e adultos a partir de 14 anos. Todas as crianças dos cursos de musicalização infantil e básico em música participavam desse Coral Infantil além dos alunos do Curso Intermediário, até a faixa etária de 16 anos.

Posteriormente houve uma demanda de crianças, não vinculadas aos cursos de extensão da Escola de Música da UFRJ, interessadas em participar do Coral Infantil. Atualmente o Coral Infantil atende 40 crianças e adolescentes entre 7 e 16 anos servindo também como campo de estudo para alunos dos cursos de licenciatura e bacharelado em música e do programa de pós-graduação em música.

Não há exigência de conhecimento musical anterior para a entrada no grupo não sendo a criança submetida a nenhum tipo de seleção. Ao ingressar no coro, são realizados alguns vocalizes com a criança para identificar seu timbre, tessitura e extensão vocal. Ao início de cada ensaio, são realizados exercícios de preparação vocal, com vocalizes, que visam o aquecimento e desenvolvimento técnico vocal da criança. Essa preparação vocal é realizada, na maioria das vezes, pela própria regente do coro.

O repertório do Coral Infantil é bastante variado, de maneira a proporcionar às crianças experiência com diversos estilos musicais. Ao longo desses 26 anos o repertório compôs-se de música popular brasileira, música folclórica nacional e internacional, canções nacionais, canções tradicionais internacionais, obras corais de compositores brasileiros e estrangeiros, óperas e obras sinfônicas.

\section{A PESQUISA E OS RESULTADOS}

Foram elaborados dois diferentes instrumentos para as finalidades específicas da presente pesquisa. Além dos questionários aplicados a 40 crianças do Coral Infantil da UFRJ para conhecer o grupo analisado, foram realizadas também entrevistas com 15 coralistas não estudantes de música para averiguar os conteúdos musicais absorvidos pelas crianças através do trabalho coral desenvolvido. Os resultados aqui expostos são referentes a essas entrevistas. Os 15 coralistas 
entrevistados tinham entre 10 e 16 anos de idade e participavam do coro por períodos que variavam entre 4 meses até 5 anos.

O objetivo da realização de entrevistas com os 15 coralistas não estudantes de música, foi verificar o nível de aprendizagem e desenvolvimento musical adquirido por eles através da interação com a partitura, demais coralistas, regente e equipe.

O roteiro da entrevista foi composto por 18 questões sobre aspectos musicais. Para averiguação dos conhecimentos de leitura e interpretação da partitura adquiridos pelos cantores entrevistados, utilizou-se três partituras para coro que ainda não haviam sido trabalhadas com esse grupo de crianças. Essas partituras foram entregues às crianças para que, com base neste material, respondessem às questões formuladas pela entrevistadora.

1) Folclore africano - South African Suíte (I-Tshotshoza) com arranjo de Henry Leck para 3 vozes à cappela.

2) Folclore do Piauí - São João Dararão com harmonização de Francisco Braga para 3 vozes à cappela.

3) John Leavitt - Festival Sanctus para 2 vozes com acompanhamento de piano.

\begin{tabular}{|c|}
\hline $\begin{array}{l}\text { ROTEIRO DA ENTREVISTA } \\
\text { 1) No coro, você está cantando no soprano }\left(1^{\mathrm{a}} \text { voz }\right) \text {, no mezzo }\left(2^{\mathrm{a}} \text { voz }\right) \text { ou no contralto }\left(3^{\mathrm{a}} \text { voz }\right) \text { ? } \\
\text { Você sabe por quê? }\end{array}$ \\
\hline 2) Qual é o título da música? (Festival Sanctus) \\
\hline 3) Quem é o compositor? (Festival Sanctus) \\
\hline 4) Essa partitura tem quantas vozes? ( Festival Sanctus e São João Dararão) \\
\hline 5) Você sabe apontar com o dedo onde está cada voz? (Festival Sanctus e São João Dararão) \\
\hline $\begin{array}{l}\text { 6) Aponte com o dedo a voz que está começando a música. E as outras vozes o que estão } \\
\text { fazendo? (Festival Sanctus e South African Suite) }\end{array}$ \\
\hline $\begin{array}{l}\text { 7) Você sabe o que são esses sinais? Qual deles dura mais? (South African Suíte- } \\
\text { mostrando as pausas da mínima, semínima e colcheia) }\end{array}$ \\
\hline 8) Aponte com o dedo a linha da voz que você canta. (São João Dararão) \\
\hline 9) E esse sinal, o que é? (São João Dararão - mostrando o rittornelo no final da música) \\
\hline 10) Você sabe quantos compassos tem aqui? (South African Suíte $-1^{\circ}$ sistema) \\
\hline $\begin{array}{l}\text { 11) Mostrar a melodia da } 3^{a} \text { voz e perguntar o que está acontecendo (está ficando mais aguda } \\
\text { ou mais grave), depois pedir que a criança cante. (São João Dararão - } 4^{\circ} \text { sistema - } \\
\text { compassos } 2 \text { a 4) }\end{array}$ \\
\hline $\begin{array}{l}\text { 12) Tocar ou cantar a melodia da } 2^{\mathrm{a}} \text { voz e perguntar se está ficando mais aguda ou mais grave. } \\
\text { (São João Dararão- } 5^{\circ} \text { sistema - compassos de } 1 \mathrm{a} 4 \text { ) }\end{array}$ \\
\hline $\begin{array}{l}\text { 13) Mostrar os sinais de intensidade }(</ \mathrm{p} / \mathrm{mp} / \mathrm{f} / \mathrm{mf} / \mathrm{ff} / \mathrm{dim} . / \mathrm{cres} \text { ) na música e perguntar o que são } \\
\text { e como devo cantar quando vejo estes sinais (Festival Sanctus) }\end{array}$ \\
\hline $\begin{array}{l}\text { 14) Mostrar a } 3^{\mathrm{a}} \text { voz } \text { e perguntar se } \text { as figuras são iguais ou diferentes, qual é essa } \\
\text { diferença. (duração)? (São João Dararão }-2^{\circ} \text { sistema - primeiro compasso) }\end{array}$ \\
\hline $\begin{array}{l}\text { 15) Mostrar as figuras da mínima, semínima e colcheia e perguntar se a duração das três } \\
\text { é a mesma ou se é diferente. Pedir que a criança demonstre a duração das figuras batendo } \\
\text { palmas. (São João Dararão) }\end{array}$ \\
\hline $\begin{array}{l}\text { 16) E essas duas notas ligadas, o que significa? (São João Dararão - } 4^{\circ} \text { sistema - compassos } \\
5 \text { e 6) }\end{array}$ \\
\hline $\begin{array}{l}\text { 17) Mostrar o acompanhamento do piano na partitura e perguntar se ele sabe o que } \\
\text { significa esta parte. Ela é cantada ou tocada, por quem? (Festival Sanctus) }\end{array}$ \\
\hline $\begin{array}{l}\text { 18) E essas músicas têm acompanhamento de algum instrumento? Você sabe qual o } \\
\text { nome que damos à música cantada pelo coro sem acompanhamento instrumental? (South } \\
\text { African Suite e São João Dararão) }\end{array}$ \\
\hline
\end{tabular}


$\mathrm{Na}$ maior parte das questões levantadas na entrevista as respostas foram satisfatórias e consideramos os resultados muito positivos no que se refere ao aprendizado e desenvolvimento musical dos coralistas não estudantes de música. Entretanto, observamos durante a entrevista que a atenção concentrada pode interferir na qualidade da aprendizagem. Na questão 6, por exemplo, foi pedido que o coralista mostrasse a voz que estava começando as músicas e perguntou-se o que as outras vozes faziam enquanto isso. Os resultados foram: 2 coralistas não acertaram a questão; 2 responderam que as outras vozes estavam esperando para cantar; 6 responderam que as outras vozes estavam em silêncio ou caladas; 5 coralistas responderam que as outras vozes estavam em pausa.

Embora 8 coralistas não tenham atribuído a nomenclatura correta à pausa em suas respostas, podemos afirmar que eles demonstraram possuir conhecimento acerca da função das pausas. Esse fato evidencia-se na questão 7, também referente a pausas. Nesta questão 12 coralistas responderam corretamente o nome e a função das pausas. Apenas 3 coralistas não souberam responder os nomes, mas ainda assim 2 deles identificaram a função das pausas.

Outro exemplo disso ocorre na questão 13. Os coralistas ao observarem 8 sinais de intensidade na partitura, deveriam responder o que eram os sinais e como deveríamos cantar ao vêlos. Os 15 coralistas souberam explicar como seria a execução dos 8 sinais, 11 coralistas não acertaram $100 \%$ dos nomes dos sinais e apenas 4 coralistas acertaram o nome correto dos 8 sinais. Os coralistas que não acertaram todos os nomes dos sinais de intensidade tiveram dois erros em comum, responderam que mp e mf significavam muito piano e muito forte.

Não podemos considerar nesses exemplos que não houve aprendizagem e desenvolvimento musical dos coralistas que não acertaram a nomenclatura dos signos musicais descritos na partitura, o fato a ser destacado aqui é que a atenção desses coralistas esteve concentrada e direcionada para algo que consideraram relevante, ou seja, a função e utilidade desses signos musicais.

A aprendizagem e desenvolvimento musical ocorre à medida que o coralista percebe e assimila os signos contidos na partitura musical com sua função e execução. Uma vez assimilados esses signos, os coralistas poderão acumular essas experiências registradas para usá-las quando necessário.

\section{CONCLUSÃO}

Durante todo o processo de aprendizagem no coral infantil verificamos que os três estágios descritos por Sloboda ou fases descritas por Mársico estão sendo desenvolvidos. O primeiro e o segundo estágio, primeira leitura e exposição continuada à partitura estão sendo trabalhados para se chegar ao terceiro estágio: prática. 
No estágio da primeira leitura da partitura ou fase da recepção, a regente apresenta aos coralistas a partitura com a música a ser trabalhada e todos os coralistas têm a oportunidade de entrar em contato com a partitura.

Os coralistas estudantes de música realizam a leitura à primeira vista e os coralistas não estudantes de música embora nos primeiros contatos ainda não identifiquem os signos musicais, fazem a leitura com auxílio dos coralistas mais experientes até que sejam capazes de realizar sua própria leitura musical.

Passa-se então para a fase da assimilação da obra musical, onde ocorrem as repetições para aperfeiçoamento de detalhes técnicos. A essa altura o coralista não estudante de música já se familiarizou com a partitura. Embora ainda não conheça o nome das notas ou das figuras, rapidamente percebem a relação entre a linha melódica escrita e a altura do som emitido, bem como a duração das figuras positivas e negativas utilizadas, compreendendo a dinâmica da escrita musical. Tornam-se capazes de, ao olhar a partitura saber qual a voz entra primeiro e quando será sua vez de entrar. Além disso, entram em contato com a pauta musical, reconhecendo claves, símbolos de dinâmica como ff, f, mf, p, mp, pp, acentos, ritornelo entre outros.

O estágio do ensaio ou fase da interpretação é finalmente a fase de recriação da obra musical estudada, a performance que não poderia ser realizada sem os dois processos anteriores.

A sistematização dos conceitos musicais ocorre de forma contínua e muito rápida, pois as crianças as vivenciam durante todo o processo de aprendizagem das obras corais. A utilização da partitura durante a leitura das obras possibilita um contato com todas as peculiaridades que envolvem a escrita musical, associando à escrita a execução musical.

Através dos questionários e entrevistas observamos ainda que o Coral Infantil da UFRJ tem contribuido na aprendizagem e no processo de desenvolvimento musical dos coralistas e é uma atividade importante por possuir elementos essenciais à formação musical. Tanto para os coralistas estudantes de música como para os não estudantes, a atividade coral auxilia no desenvolvimento da educação auditiva e respiratória, na percepção rítmica, na compreensão fraseológica e melhoria da emissão vocal com qualidade de afinação. Além dos conhecimentos relacionados à música, o canto coral proporciona aos coralistas a oportunidade do trabalho em equipe com todos os benefícios que esta interação pode trazer coletiva e individualmente.

Para os 15 coralistas não estudantes de música entrevistados, a atividade coral foi também fundamental para a iniciação, aquisição da leitura e aperfeiçoamento musical. 


\section{REFERENCIAS}

AMATO, Rita de Cássia Fucci. O canto coral como prática sócio-cultural e educativo - musical. Revista Opus, Goiânia, v.13, p.75-96, 2007.

Habilidades e Competências na Prática da Regência Coral: um estudo exploratório. Revista da ABEM, Porto Alegre, v. 19, p. 15-26, mar. 2008

Interdisciplinaridade, música e educação musical. Revista Opus, Goiânia, v. 16, n. 1, p. 30- 47, jun. 2010.

FONTERRADA, Marisa T. de O. De tramas e fios: um ensaio sobre música e educação. $2^{\mathrm{a}}$ ed. São Paulo: UNESP, 2008.

MÁRSICO, Leda Osório. A voz infantil e o desenvolvimento músico-vocal. Porto Alegre: Escola Superior de Teologia São Lourenço de Brindes, 1979.

MATHIAS, Nelson. Coral, um canto apaixonante. Brasília: MusiMed, 1986.

SLOBODA, J.A. A mente musical: a psicologia cognitiva da música. Tradução de Beatriz Ilari e Rodolfo Ilari. Londrina. EDUEL, 2008. 